\title{
Neurons of Origin and Fiber Trajectory of Amygdalofugal Projections to the Medial Preoptic Area in Syrian Hamsters
}

\author{
WILLIAM F. MARAGOS, SARAH WINANS NEWMAN, MICHAEL N. LEHMAN, \\ AND J. BRADLEY POWERS \\ Department of Anatomy and Cell Biology, Medical Science II, University of Michigan \\ Medical School, Ann Arbor, Michigan 48109-0616
}

\begin{abstract}
The amygdaloid neurons of origin and the trajectory of amygdaloid fibers to the medial preoptic area of the adult male Syrian hamster were identified by using horseradish peroxidase (HRP) histochemistry. After iontophoresis of HRP into the medial preoptic area, retrogradely labeled amygdaloid neurons were located in the dorsal and caudal parts of the medial amygdaloid nucleus and throughout the amygdalohippocampal area. No amygdaloid neurons were labeled after HRP applications confined to the most rostral portion of the medial preoptic area (anterior to the body of the anterior commissure). Following more caudal medial preoptic area injections (body of the anterior commissure to the suprachiasmatic nucleus) the distribution of retrogradely labeled cells in the medial amygdaloid nucleus and the amygdalohippocampal area revealed no topographic organization of the amygdalopreoptic connections. When amygdaloid neurons were labeled, the amygdalohippocampal area contained two to five times as many HRP-filled cells as the medial amygdaloid nucleus.

Retrogradely transported HRP could be followed from the medial preoptic area to the amygdala through fibers in the dorsomedial quadrant of the stria terminalis. In addition, electrolytic lesions of the stria terminalis prior to iontophoresis of HRP into the medial preoptic area prevented retrograde transport to neurons in both the dorsocaudal medial amygdaloid nucleus and the amygdalohippocampal area.

These results confirm earlier observations describing the location of autoradiographically labeled efferents from the medial amygdaloid nucleus to the medial preoptic area and provide new information about the restricted region within the medial amygdaloid nucleus from which these projections arise. They also suggest that, unlike the projections from the medial amygdaloid nucleus to the bed nucleus of the stria terminalis, the efferents to the medial preoptic area travel entirely in the stria terminalis.
\end{abstract}

Key words: amygdaloid body, horseradish peroxidase, limbic system, olfactory pathways, rodentia

The medial preoptic area in the basal telencephalon is generally considered a neuroanatomical and neuroendocrinological substrate underlying male sexual behavior (Malsbury and Pfaff, '75; Larsson, '79). In rats and golden hamsters the complete loss of copulatory behavior has been observed following bilateral medial preoptic area lesions, (Heimer and Larsson, '66; Lisk, '68; Giantonio et al., '70; Caggiula et al., '73; Christensen et al., '77; Szechtman et al., '78; Hansen et al., '82; Eskes, '84; Powers et al., '87).
Implantation of testosterone into the medial preoptic area, a region in which some cells accumulate testosterone (Sar and Stumpf, '75) and its metabolites (Sar and Stumpf, '77; Doherty and Sheridan, ' 81 ), reinstated the complete copulatory sequence in many of the animals that had ceased mating following castration (Davidson, '66; Lisk, '67; Chris-

Accepted August 18, 1988.

() 1989 ALAN R. LISS, INC. 
tensen and Clemens, '74; Lisk and Bezier, '80). In addition, facilitation of sexual behavior has been observed following electrical stimulation to this region in rats (Malsbury, '71; Merari and Ginton, '75).

In both rats and hamsters the corticomedial amygdala, which includes the medial and cortical nuclei and the amygdalohippocampal area, has also been implicated in the expression of male copulatory behavior. Specifically, the corticomedial amygdala may be an area for integration of steroid hormone and chemosensory inputs that control mating behavior. Like the medial preoptic area, the corticomedial amygdala contains neurons that accumulate testosterone (Sar and Stumpf, '75) and its metabolites in the male (Sar and Stumpf, '77; Doherty and Sheridan, '81) and in addition neurons whose electrophysiological properties are altered in the absence of testosterone (Kendrick and Drewett, '79; Kendrick, '82a,b). Within the corticomedial amygdala the sexually dimorphic medial nucleus (Nishizuka and Arai, '81a,b) and the posteromedial cortical nucleus are known to receive olfactory information indi-

\section{Abbreviations}

\begin{tabular}{|c|c|}
\hline $\mathrm{AC}$ & anterior commissure \\
\hline $\mathrm{ADPN}$ & anterodorsal preoptic nucleus \\
\hline $\mathrm{AH}$ & anterior hypothalamus \\
\hline AHA & amygdalohippocampal area \\
\hline ALAC & anterior limb of the anterior commissure \\
\hline AOB & accessory olfactory bulb \\
\hline AVPN & anteroventral preoptic nucleus \\
\hline BLa & basolateral nucleus, anterior part \\
\hline BLp & basolateral nucleus, posterior part \\
\hline BM & basomedial nucleus \\
\hline BNST & bed nucleus of the stria terminalis \\
\hline BNSTe & bed nucleus of the stria terminalis, external part \\
\hline BNST1 & bed nucleus of the stria terminalis, lateral part \\
\hline BNSTm & bed nucleus of the stria terminalis, medial part \\
\hline $\mathrm{Ce}$ & central nucleus \\
\hline CP & cerebral peduncle \\
\hline $\mathrm{C} 1$ & anterior cortical nucleus \\
\hline $\mathrm{C} 2$ & posterolateral cortical nucleus \\
\hline C3 & posteromedial cortical nucleus \\
\hline DG & dentate gyrus \\
\hline End & endopiriform nucleus \\
\hline $\mathbf{F}$ & fornix \\
\hline HRP & horseradish peroxidase \\
\hline La & lateral nucleus, anterior part \\
\hline Lp & lateral nucleus, posterior part \\
\hline LPOA & lateral preoptic area \\
\hline LSv & lateral septum, ventral part \\
\hline M & medial nucleus of the amygdala \\
\hline MEPO & median preoptic nucleus \\
\hline MI & massa intercalata \\
\hline MOB & main olfactory bulb \\
\hline MPOA & medial preoptic area \\
\hline MPOAH & medial preoptic area/anterior hypothalamic junction \\
\hline MPN & medial preoptic nucleus \\
\hline MPNc & medial preoptic nucleus, central part \\
\hline MPNmag & medial preoptic nucleus, magnocellular part \\
\hline NAC & nucleus of the anterior commissure \\
\hline NAOT & nucleus of the accessory olfactory tract \\
\hline NLOT & nucleus of the lateral olfactory tract \\
\hline $\mathrm{OC}$ & optic chiasm \\
\hline OT & optic tract \\
\hline OVLT & organum vasculosum of the lamina terminalis \\
\hline PDPN & posterodorsal preoptic nucleus \\
\hline POC & primary olfactory cortex \\
\hline PSN & parastrial nucleus \\
\hline PVN & paraventricular nucleus \\
\hline PVpo & periventricular preoptic nucleus \\
\hline SCN & suprachiasmatic nucleus \\
\hline SM & stria medullaris \\
\hline ST & stria terminalis \\
\hline Sub & subiculum \\
\hline Th & amygdalo-entorhinal transition area \\
\hline & \\
\hline
\end{tabular}

rectly from the main olfactory bulb (Krettek and Price, '78b; Kevetter and Winans, '81b; Ottersen, '82) and vomeronasal information directly from the accessory olfactory bulb (Scalia and Winans, '75; Broadwell, '75). The amygdalohippocampal area (Krettek and Price, '78b), which was originally described by Brodal ('47) and previously known as the "caudal medial nucleus," receives vomeronasal input indirectly by way of the projections from the accessory olfactory bulb to the posteromedial cortical amygdaloid nucleus and from this nucleus to the amygdalohippocampal area (Meredith, '80).

In the male hamster, chemosensory information from both vomeronasal and olfactory receptors has been shown to be critical for the initiation and maintenance of mating behavior (Murphy and Schneider, '70; Winans and Powers, '77). Furthermore, bilateral electrolytic lesions of the medial amygdaloid nucleus have been shown to produce the same deficits in male sexual behavior in the hamster as combined olfactory and vomeronasal nerve deafferentation (Lehman et al., '80; Lehman and Winans, '82). Thus it appears that the corticomedial amygdala, particularly the medial nucleus, plays an important role in processing hormonal and chemosensory information essential for normal male copulatory behavior.

Numerous studies in the rat with a variety of techniques have verified the existence of a component of the stria terminalis that contains fibers projecting from the corticomedial amygdala to the medial preoptic area (Leonard and Scott, '71; deOlmos, '72; Krettek and Price, '78a). However, in spite of the importance of both the medial amygdaloid nucleus and the medial preoptic area in the expression of sexual behavior in the hamster, surprisingly little is known about the connections from the amygdala to the preoptic area in this species. Our laboratory has presented autoradiographic evidence for the existence of a terminal field in the medial preoptic area following injections of [3-H]amino acids into the medial amygdaloid nucleus of male hamsters (Kevetter and Winans, '81a). Analysis of this material has also revealed that most of the projection fibers from the medial nucleus appear to travel in the stria terminalis (Kevetter and Winans, '81a). This technique, however, did not allow us to determine the total pattern and precise locations of cells of origin within the corticomedial amygdala. We have thus utilized the horseradish peroxidase (HRP) retrograde transport technique. We have made both large applications in the medial preoptic area, in order to determine the location of all cells projecting into this region from the amygdala, and small applications, to determine the boundaries of the terminal field within the medial preoptic area.

Other work in this laboratory has demonstrated the existence of a ventral pathway, in addition to the stria terminalis, by which the bed nucleus of the stria terminalis receives information from the corticomedial amygdala (Lehman and Winans, '83). In order to determine whether the medial preoptic area also receives corticomedial amygdala projections by more than one pathway, we have selectively lesioned fibers of the stria terminalis prior to injections of HRP into the medial preoptic area.

\section{MATERIALS AND METHODS Animals}

Fifty-three male Syrian hamsters (Mesocricetus auratus) weighing 110-125 g were used in this study. The animals (Engle Laboratory Animals, Farmersburg, IN) were housed 
individually with food and water available ad lib and maintained on a 14-hour-light/10-hour-dark illumination cycle.

\section{Horseradish peroxidase iontophoresis}

HRP (Miles, Elkhart, IN) was dissolved in $50 \mathrm{mM}$ Tris buffer, $\mathrm{pH} 8.6$, to a concentration of $33 \%$ (wt/vol). Each animal was anesthetized with sodium pentobarbital $(85 \mathrm{mg} /$ $\mathrm{kg}$ ) and placed in a Kopf stereotaxic apparatus. The skull was exposed and horizontally aligned. A small hole was drilled in the skull, the dura was incised, and a glass micropipette (tip diameter 10-25 $\mu \mathrm{m}$ ) filled with HRP was lowered through the surface of the brain. Anodal current of $0.1 \mu \mathrm{A}$ (Grass Stimulator, S-44) was applied to minimize leakage of the HRP during penetration of the brain. Vertical ipsilateral and angled contralateral approaches to the application sites were employed. Injections lasting 10-25 minutes were made with $1 \mu \mathrm{A}$ cathodal square-wave pulses of $500-\mathrm{msec}$ duration. At the end of the injection period, the stimulator was turned off and the pipette remained in place for several minutes. Anodal current $(0.1 \mu \mathrm{A})$ was again applied during withdrawal of the pipette.

Following a survival period of 40-48 hours, the animals were deeply anesthetized with sodium pentobarbital $(85$ $\mathrm{mg} / \mathrm{kg}$ ), and perfused through the left ventricle with a wash of a $250-\mathrm{ml}$ solution of $67 \mathrm{mM}$ cacodylate buffer that contained $0.8 \%$ sucrose, $0.8 \%$ sodium chloride, and $0.4 \%$ dextrose maintained at body temperature. One gram per liter of sodium nitrite was added to the wash in order to dilate the blood vessels. The wash was followed immediately by perfusion with $250 \mathrm{ml}$ of $67 \mathrm{mM}$ cacodylate-buffered $3 \%$ glutaraldehyde fixative, which contained $4 \%$ sucrose. Both wash solution and fixative were filtered before use. The brain was removed from the skull and stored in $20 \%$ sucrose-wash solution overnight at $4^{\circ} \mathrm{C}$.

\section{Stria terminalis lesions}

Eleven hamsters were anesthetized and received bilateral electrolytic lesions of the stria terminalis by stereotaxically lowering an insect pin electrode (tip diameter $0.37 \mathrm{~mm}$ ) insulated except for $0.5 \mathrm{~mm}$ at the tip. A DC current of 2 $\mathrm{mA}$ was delivered for 15 seconds. Stereotaxic coordinates for the strial lesions were AP $+0.2, \mathrm{ML}+2.0$ from bregma, and DV -5.1 to -5.5 from dura, with bregma and lambda in a horizontal plane. Thirty days after surgery (during which time animals were behaviorally tested) both striallesioned and sham-lesioned animals received HRP applications to the medial preoptic area and were perfused, and the brains were stored as previously described.

\section{Histological analysis}

Brains from both groups were mounted on a freezing microtome, and 50- $\mu \mathrm{m}$ sections were cut and stored in a phosphate-buffered solution of $25 \%$ ethylene glycol and $25 \%$ sucrose at $-10^{\circ} \mathrm{C}$. Within 24 hours, every fourth section was stained for HRP by using the TMB method according to deOlmos et al. ('78). Adjacent sections were stained for Nissl substance using cresyl violet. Light- and darkfield illumination was used for microscopic analysis. By using a microprojector, labeled cells were plotted on tracings of adjacent amygdala sections and counted. To reconstruct stria terminalis lesions, microprojector tracings of all sections containing the lesion were made. The determination of the zones from which HRP is taken up and retrogradely transported have been described previously (Newman and Winans, '80).

\section{RESULTS}

The cytoarchitecture of the medial preoptic area in the rat has been described by a number of investigators (Gurd. jian, '27; Swanson, '76; Bleier, '82; Simerly et al., '84). The only description of the hamster medial preoptic area is by Bleier et al. ('82), with which we disagree on the caudal limits of both the medial preoptic area and the medial preoptic nucleus. Therefore, a brief description of this region in the hamster is necessary for an understanding of our experimental results.

\section{Boundaries of MPOA}

Rostrally (Fig. 1A), the medial preoptic area extends anteriorly beyond the body of the anterior commissure to the level of the organum vasculosum of the lamina terminalis. At this level, the medial preoptic area is bordered dorsally by the anterior limb of the anterior commissure and the septum and laterally by the lateral preoptic area. More caudally (Fig. 1B) the dorsal medial preoptic area is limited solely by the body of the anterior commissure and laterally by the lateral preoptic area, in which the cells are less densely packed and more lightly stained. Caudal to the body of the anterior commissure (Fig. 1D) the medial preoptic area is still bordered laterally by the lateral preoptic area, but at this point the stria medullaris/fornix complex and the bed nucleus of the stria terminalis form the dorsal boundary. Similarities in architecture between the medial preoptic area and the anterior hypothalamus caudal to it make the determination of the caudal boundary a rather difficult one. On the basis of tract-tracing findings and cytoarchitectural observations we have determined that the medial preoptic area terminates at the rostral limit of the suprachiasmatic nucleus (Fig. 1H). This is in agreement with the studies of Simerly et al. ('84) and Saper et al. ('78) in the rat, but not with the description by Bleier et al. ('82) of the medial preoptic area in the hamster.

\section{Nuclear groups of the medial preoptic area}

The medial preoptic area was classically described as a homogeneous region made up of a diffuse collection of darkly staining cells. More recent work, however, indicates that there exist a number of subnuclei, readily observable in Nissl-stained material under the light microscope (Simerly et al., '84). Located within the most rostral level of the medial preoptic area (Fig. 1A) is the midline median preoptic nucleus (Swanson, '76). The small, darkly staining cells of this nucleus appear to extend ventrolaterally into an area that also contains larger, pale-staining neurons with prominent nucleoli. In hamster material this group of mixed cell types, the anteroventral preoptic nucleus, is first seen rostral to the medial preoptic nucleus and then extending caudally on the lateral edge of the medial preoptic nucleus all the way to the caudal border of the body of the anterior commissure (Fig. 1A-C). Simerly and Swanson ('86) show the anteroventral preoptic nucleus in a similar location in the rat, but extending only to midcommissural levels.

Also in the rostral medial preoptic area is the anterodorsal preoptic nucleus, which corresponds to the nucleus of the same name in the rat, as described by Simeriy et al.('84). These investigators have thoroughly discussed the nomenclature for this area in the hands of previous investigators.

The rostral part of the hamster medial preoptic area contains a distinctive cluster of fusiform neurons that correspond well to the description of the parastrial nucleus in the rat by Simerly et al. ('84). In the hamster, this cell 


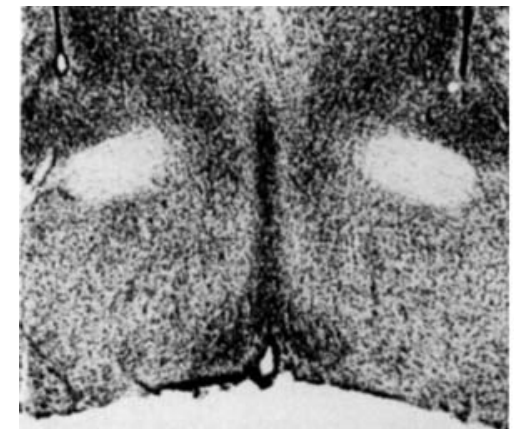

A
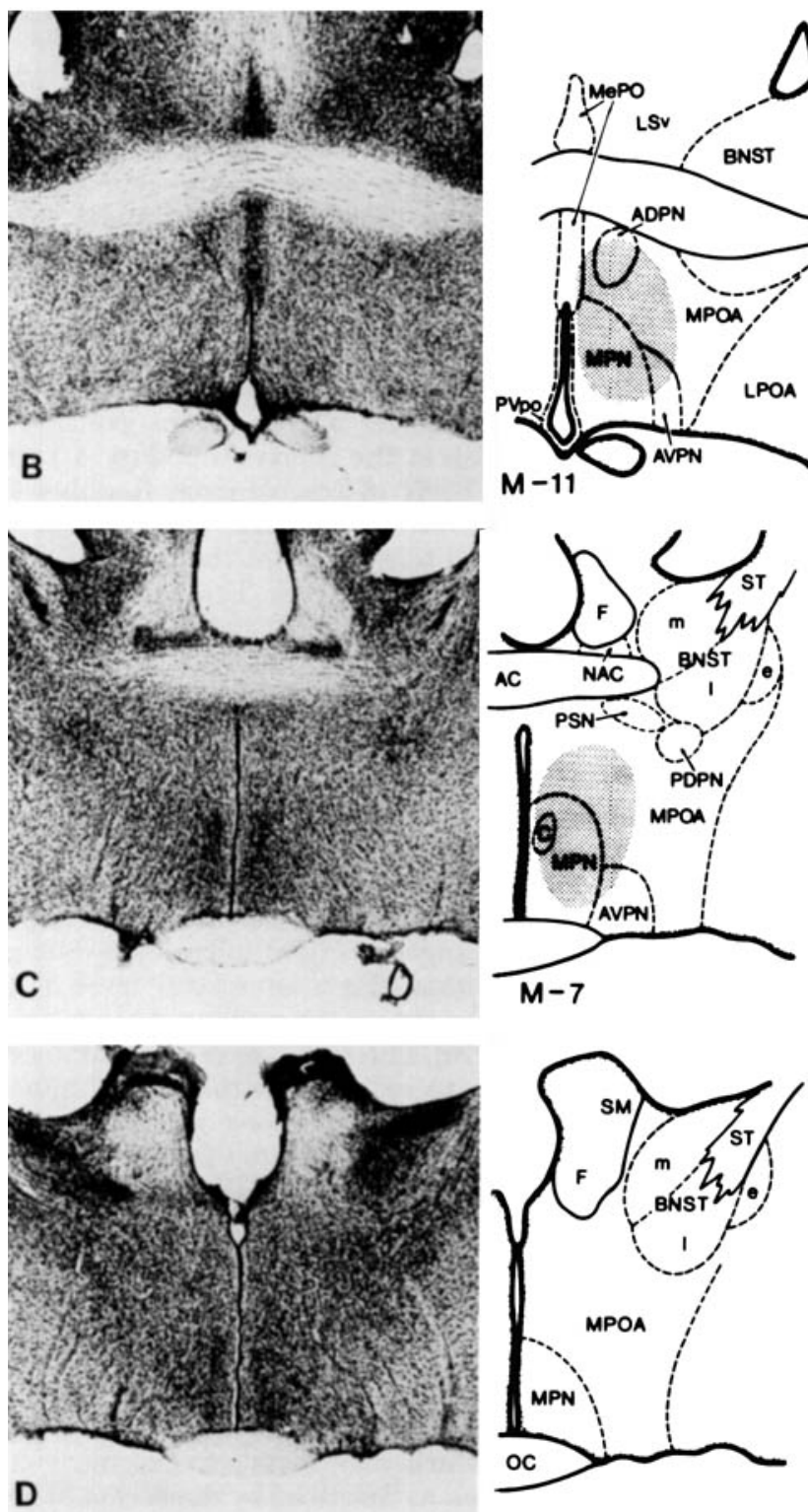

Fig. 1. Photomicrographs of cresyl-violet-stained sections $(80 \mu \mathrm{m})$ at selected rostrocaudal levels $(\mathbf{A}-\mathrm{H})$ through the medial preoptic area of the male hamster. Line drawings illustrate nuclei within the medial preoptic
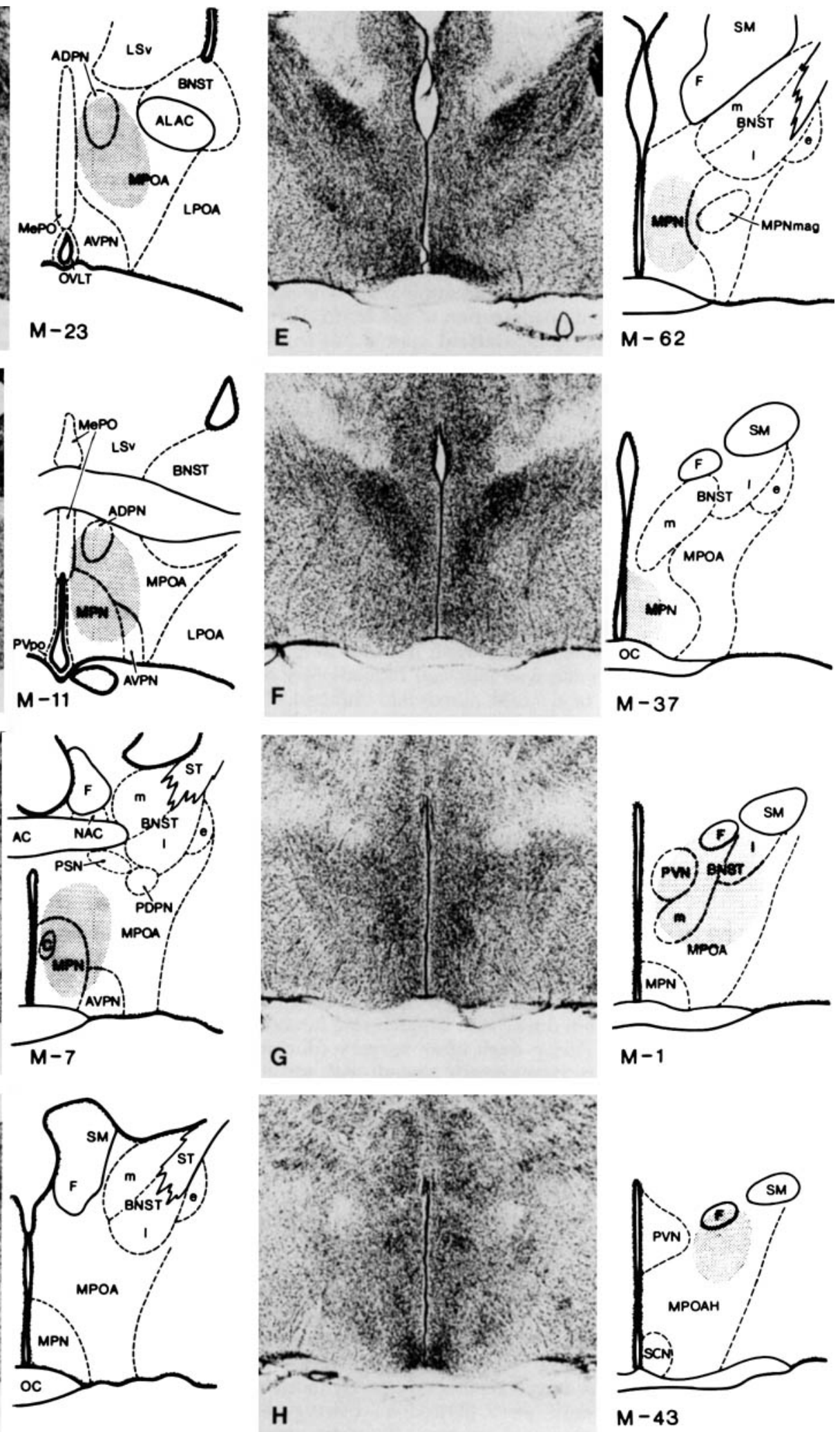

area. Stippled areas show the largest extent (center) of the HRP iontophoresis site in each of seven different experimental animals (M-23, M-11, M-7, $\mathrm{M}-62, \mathrm{M}-37, \mathrm{M}-1$, and $\mathrm{M}-43$ ) 
group disappears under the caudal part of the body of the anterior commissure (Fig. 1C), whereas in the rat, the parastrial nucleus extends further caudally, to the rostral border of the paraventricular nucleus. At its caudalmost point in both species, the parastrial nucleus lies medial to the posterodorsal preoptic nucleus, a small but prominent group of large, darkly stained cells (Fig. 1C). The posterodorsal preoptic nuclei of the rat and hamster are similar both in cytoarchitecture and in their relationship to the parastrial nucleus and the bed nucleus of the stria terminalis (Simerly et al., ' 84 ), but the posterodorsal preoptic nucleus of the hamster is more rostrally located within the medial preoptic area.

The largest nucleus of the medial preoptic area is the medial preoptic nucleus. In both the rat (Simerly et al., ' 84 ) and hamster material, the medial preoptic nucleus extends from the most rostral border of the body of the anterior commissure to the anterior hypothalamic area. Bleier et al. ('82) divide this nucleus into a rostral half, the medial preoptic nucleus, and a caudal half, the anterior hypothalamic nucleus, but their photographs of Nissl-stained sections of hamster brain correspond precisely with what we have chosen to describe as a single nucleus, on the basis of its connections with the amygdala, on the basis of its cy. toarchitectonic homogeneity, and on a widely accepted definition of the caudal boundary of the medial preoptic area at the rostral end of the suprachiasmatic nucleus (Saper et al., '78).

Through most of its rostrocaudal extent the medial preoptic nucleus occupies the ventromedial quadrant of the medial preoptic area in the hamster. It is not clearly separated from the periventricular preoptic nucleus medially or the optic chiasm ventrally and shows minimal variation in cell types and density of cell packing, with the exception of a small, very dense cluster of neurons which is found dorsomedially at midrostrocaudal levels of the medial preoptic nucleus (Fig. 1C). We have tentatively called this the central medial preoptic nucleus corresponding to the rat's central medial preoptic nucleus (Simerly et al., '84) on the basis of its cytoarchitecture, overall size, and position within the medial preoptic nucleus. Our analysis indicates that a separate subgroup of densely packed cells that Bleier et al. ('82) considered the hamster equivalent of the rat's central medial preoptic nucleus (or SDN-POA of Gorski et al., '78) is, in fact, as they suggest alternatively, the caudal part of the bed nucleus of the stria terminalis. (Compare Fig. 1G with Bleier et al., '82, Figs. 22b and 23b.)

In the midcaudal region of the medial preoptic area we have named a prominent nucleus that was illustrated and described by Bleier et al. ('82, their Fig. 21b) as part of the anterior hypothalamic area. This oval nucleus extends laterally from the medial preoptic nucleus over a rostrocaudal distance of approximately $250 \mu \mathrm{m}$ and is composed of the largest cells of the entire medial preoptic area; we have designated it the magnocelluar medial preoptic nucleus (Fig. 1E).

\section{Applications of HRP}

Iontophoretic applications of HRP were made at various rostrocaudal levels of the medial preoptic area and the anterior hypothalamus. The centers of injection sites at six selected levels of the medial preoptic area and a control injection in the medial preoptic area/anterior hypothalamic junction are shown in Figure 1. HRP was taken up at neuron terminals and transported to cell bodies in the amygdala from iontophoresis sites within the caudal four- fifths of the medial preoptic area beginning beneath the body of the anterior commissure (Figs. 1B-G, 6). Applications of HRP into the medial preoptic area rostral to this region (Fig. 1A) revealed no transport to the amygdala. Injection sites that involved the medial division of the bed nucleus of the stria terminalis (Fig. 1G) produced a different pattern of labeled cells in the amygdala than those confined to the medial preoptic area (see below). Control injections in the perifornical region at the level of the suprachiasmatic nucleus (Fig. $1 \mathrm{H}$ ) were analyzed to evaluate the potential for labeling fibers passing through this area to termination sites in the mediobasal hypothalamus. These cases also produced a different pattern of labeled cells than after the medial preoptic area injections.

Further, these experiments have revealed that the terminal field from the amygdala does not include the most ventral or periventricular portions of the medial preoptic area. Animals that received small, circumscribed iontophoretic injections of HRP confined to either of these areas had no cells labeled in the amygdala. Substantial cell labeling in the amygdala, however, was observed in brains that received injections in the central medial preoptic area in cluding the medial preoptic nucleus. There was no difference in the pattern of cells labeled in the amygdala following injections that were made by using the ipsilateral or contralateral angled approach.

\section{Cell labeling in the amygdala}

The medial nucleus and the amygdalohippocampal area were the only amygdaloid nuclei in which HRP-labeled cells were observed following applications into the medial preoptic area (Figs. 2, 3). Regardless of the site of application of HRP in the core of the caudal four-fifths of the medial preoptic area, a similar pattern of labeling in the amygdala was observed.

In the medial amygdaloid nucleus (Fig. 4 and most rostral section in Fig. 5), almost all of the stained cells were located in the caudal two-thirds of the nucleus, most particularly in the dorsal aspect. Note that Figure 4 does not illustrate the most rostral levels of the medial amygdaloid nucleus. In all brains analyzed, only one or two labeled cells were ever seen in the rostral one-third or ventral region of this nucleus. In a number of brains, a cluster of cell bodies in the dorsocaudal portion of the medial nucleus was surrounded by what appeared to be a terminal field (Fig. 2). Evidence in the rat suggests reciprocal connections to the medial amygdaloid nucleus from cells of the medial preoptic area (Conrad and Pfaff, '76; Ottersen, '80). The data presented here for the hamster support this conclusion; however, the histochemical incubation period that we routinely employed was not long enough for the consistent development of reaction product in terminal fields. Thus, we can make no definitive statements about these connections in the hamster.

The amygdalohippocampal area was the only other amygdaloid nucleus containing HRP-stained cells, and the num ber of cells and pattern of labeling observed in this nucleus were noticeably different from those in the medial amyg. daloid nucleus (Figs. 4,5). When the total number of labeled cells from all sections through the amygdalohippocampal area and the medial amygdaloid nucleus were counted in each brain, from two to five times as many labeled cells were observed in the amygdalohippocampal area as in the medial amygdaloid nucleus. In an animal with one of the largest application sites (Fig. $6 \mathrm{M}-7$ ), $50 \mathrm{HRP}$-labeled cells were counted in the amygdalohippocampal area whereas 

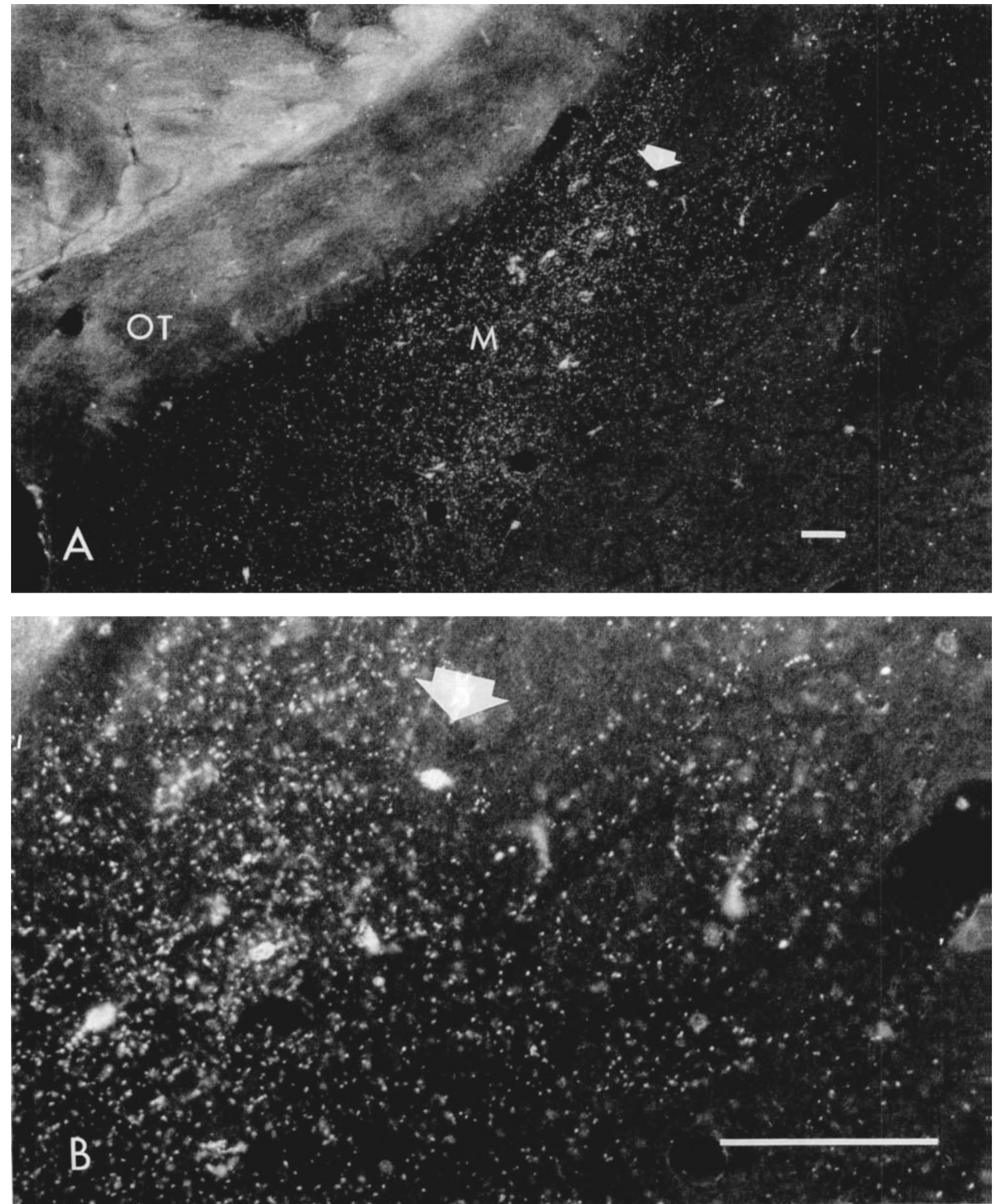

Fig. 2. Photomicrographs of the medial nucleus of the amygdala. A: A low-magnification photomicrograph shows the position of the labeled cells in the dorsal part of the nucleus and the terminal field over this but not the adjacent nuclei; B: A higher-power photomicrograph illustrates the morphology of the labeled cells. The arrows in A and $\mathrm{B}$ point to the same cell for orientation. Each measure bar represents $100 \mu \mathrm{m}$. 

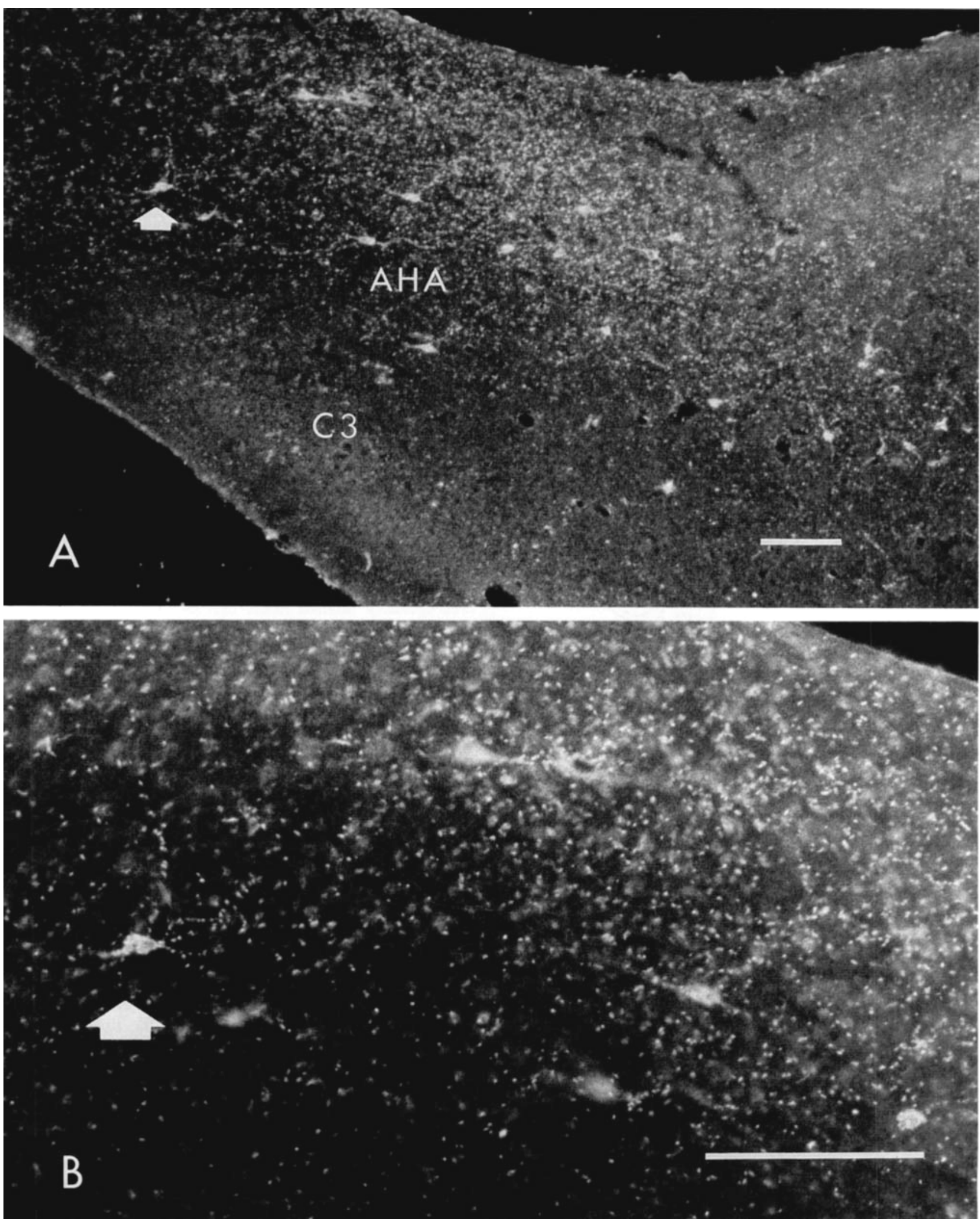

Fig. 3. Photomicrographs of the amygdalohippocampal area. A: A lowmagnification photomicrograph illustrates the terminal field over this nuclear area and the distribution of labeled cells throughout the area. B: At higher magnification the cell morphology of retrogradely labeled neurons is shown. The arrows in A and B point to the same cell. Each measure bar represents $100 \mu \mathrm{m}$. 


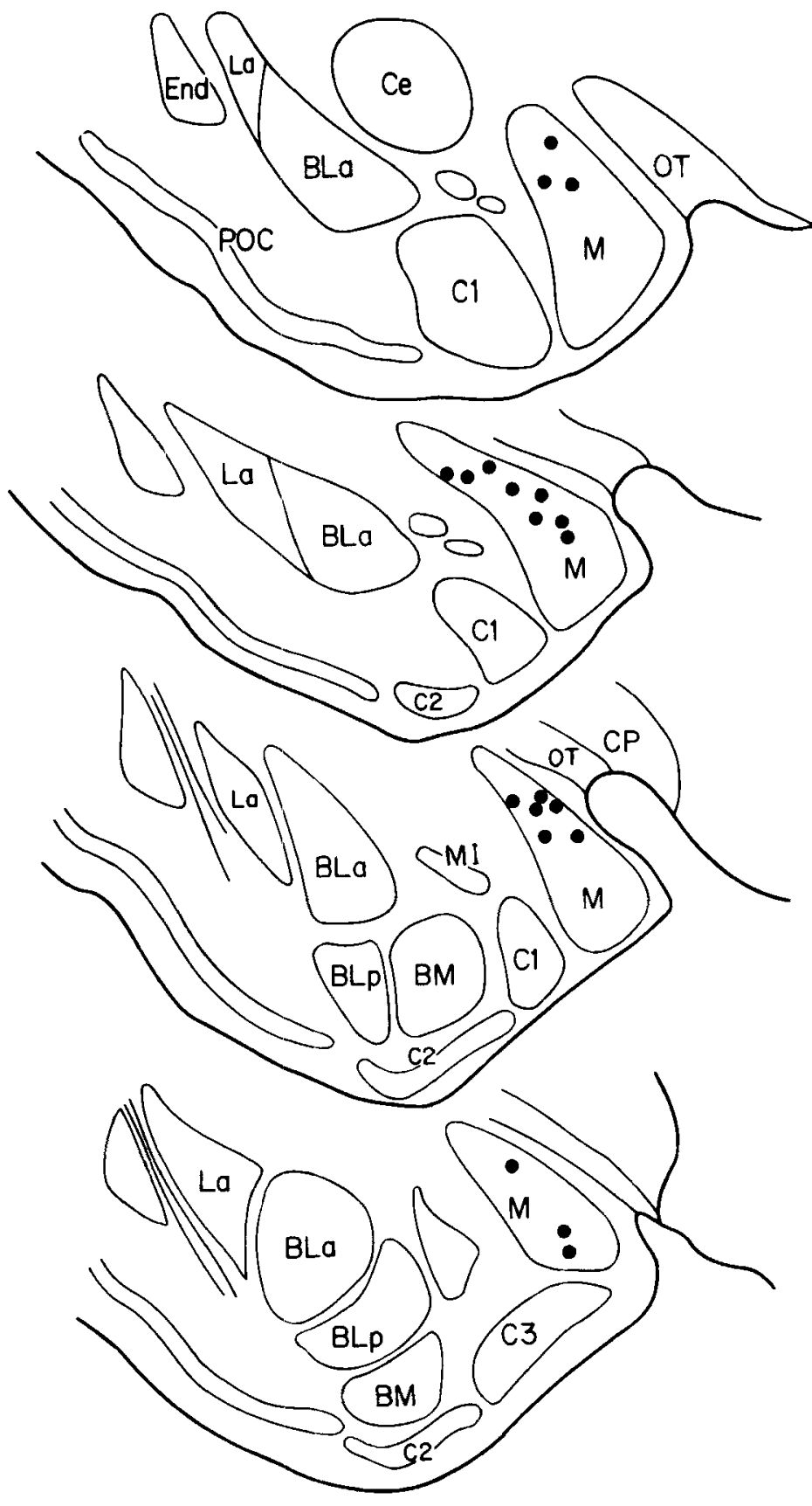

Fig. 4. Schematic representation of the distribution of HRP- filled neurons in middle and caudal parts of the medial amygdaloid nucleus after HRP iontophoresis into the medial preoptic area.

only 11 were found in the medial amygdaloid nucleus. This consistent observation of a greater number of labeled cells in the amygdalohippocampal area thus appears to represent a quantitative difference between efferent projections from these two nuclei to the medial preoptic area.

In contrast to the medial amygdaloid nucleus, in which labeled cells were restricted to the dorsocaudal two-thirds the nucleus, labeled cells in the amygdalohippocampal area were evenly distributed at all levels examined throughout its entire rostrocaudal extent (Fig. 5). As in the medial amygdaloid nucleus, what appeared to be a terminal field was easily observed surrounding a group of cells in the amygdalohippocampal area in several of the brains (Fig. 3).

When the medial part of the bed nucleus of the stria terminalis was involved in the HRP iontophoresis site (Fig. 1G), HRP-filled cells were observed not only in the dorsocaudal medial nucleus and the amygdalohippocampal area but also in the rostral part of the medial nucleus, a finding consistent with observations after injections of HRP into the bed nucleus of the stria terminalis (Lehman and Winans, ' 83 ). In the brains in which a control iontophoresis site was placed in the perifornical medial preoptic area at the anterior hypothalamic junction (Fig. 1H), very few neurons were labeled in the amygdala and these were restricted to the rostroventral part of the medial amygdaloid nucleus.

\section{Stria terminalis lesions}

In all animals with effective transport to the amygdala, we observed retrogradely labeled fibers entering the dorsomedial division of the stria terminalis and fibers exiting it into the amygdala. In order to test the hypothesis that the stria terminalis was the only route by which cells in the amygdala projected to the medial preoptic area, we made iontophoretic applications of HRP into the medial preoptic area of animals in which we previously had destroyed the stria terminalis. Figure 7 illustrates a series of coronal sections of one animal (H-286) that underwent such a procedure, juxtaposed to a coronal series from animal M-7, which received only an HRP injection into the medial preoptic area.

In both instances, fairly large application sites can be seen to fill most of the medial preoptic area. In addition, retrogradely labeled fibers can be followed dorsolaterally through the bed nucleus of the stria terminalis toward the stria terminalis in both animals. In experimental animal M-286, however, labeled fibers could be followed in the stria just rostral to the lesion, but not beyond it. No cells were labeled in the medial amygdaloid nucleus or the amygdalohippocampal area. This result was consistently observed in hamsters with complete stria terminalis destruction. In M-7, on the other hand, fibers could be followed caudally in the stria terminalis and labeled cells could be observed as previously described in both the medial amygdaloid nucleus and the amygdalohippocampal area.

\section{DISCUSSION}

The data presented here provide additional evidence for the existence of a fiber projection from the medial amygdaloid nucleus and the amygdalohippocampal area to the medial preoptic area in the hamster. These results confirm autoradiographic data from this laboratory, which indicated the existence of a terminal field in the caudal portion of the medial preoptic area following injections of [3$\mathrm{H}$ ]amino acids into the medial amygdaloid nucleus (Kevetter and Winans, '81a). In addition, these HRP tract-tracing data suggest that the terminal fields of fibers originating in the medial amygdaloid nucleus and the amygdalohippocampal area are congruent, since cell labeling always occurred in both nuclei following HRP injections into any part of the caudal four-fifths of the medial preoptic area. Moreover, by making small, circumscribed injections, we have localized the boundary of the terminal field from the amygdala to be the central region, or core of the medial preoptic area, not extending into the periventricular preoptic area or the most ventral portion of the medial preoptic area itself. Results from neither $\left[{ }^{3} \mathrm{H}\right]$ amino acid injections 


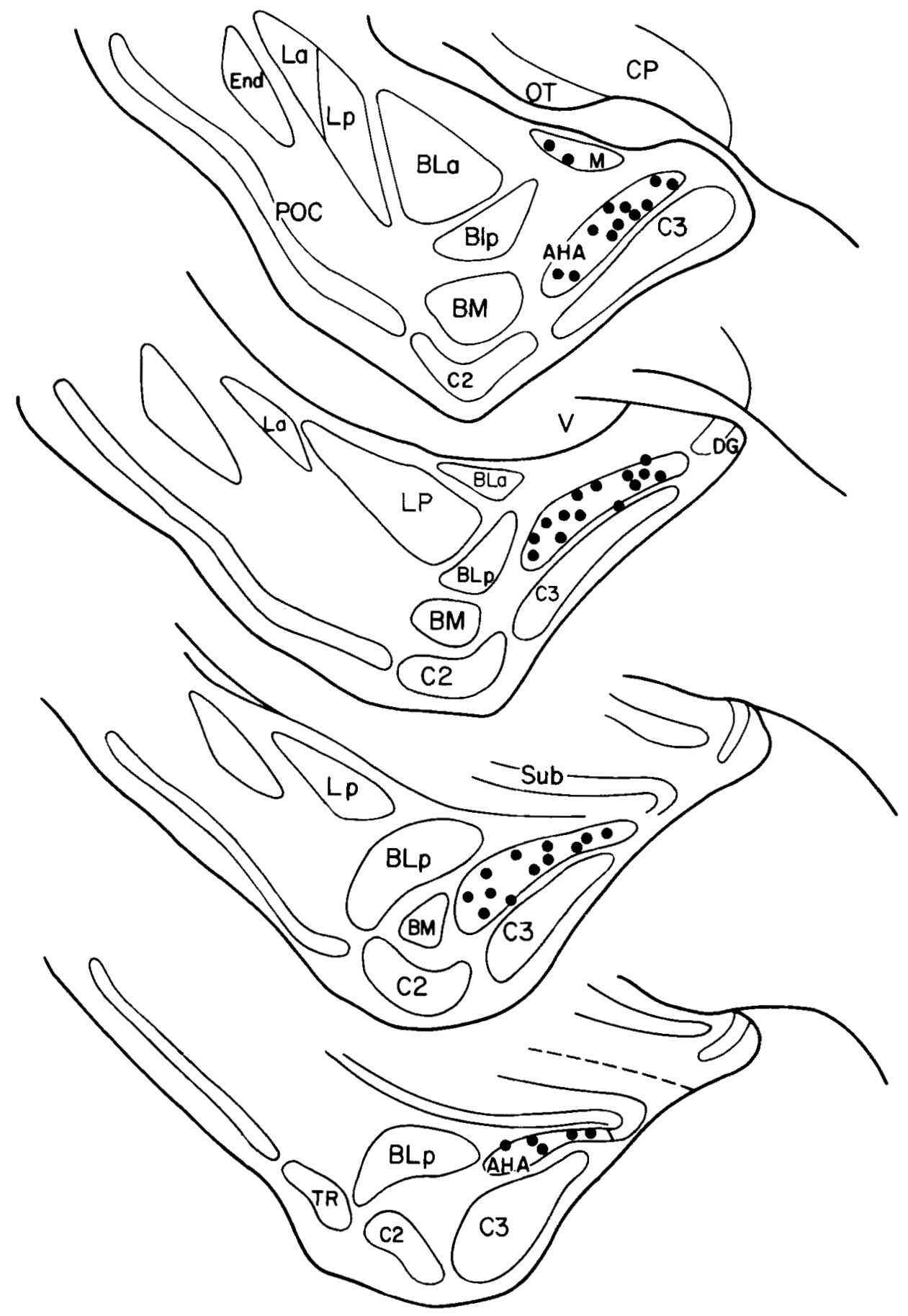

Fig. 5. Schematic representation of the distribution of HRP. filled neurons in the most caudal part of the medial amygdaloid nucleus and in the

into the medial amygdaloid nucleus nor HRP injections into the medial preoptic area, however, suggest that this terminal field is confined to any one of the cytoarchitectonic areas within the medial preoptic area described above.

Analysis of this HRP material also revealed a distinct pattern of cell labeling in the medial amygdaloid nucleus and the amygdalohippocampal area following HRP applications in the medial preoptic area. In the medial nucleus, labeled cells were sparsely distributed over the caudal two- amygdalohippocampal area after HRP iontophoresis into the medial preoptic area.

thirds of the nucleus and limited to the dorsal region. In contrast, approximately two to five times as many cells were spread over the entire area of the amygdalohippocampal area and distributed throughout its rostrocaudal extent. In no instance, however, was there evidence of a topographic organization to these projections.

Lastly, these data confirmed previous observations that the fiber projections from the amygdala to the medial preoptic area travel collectively in the dorsomedial portion of the 


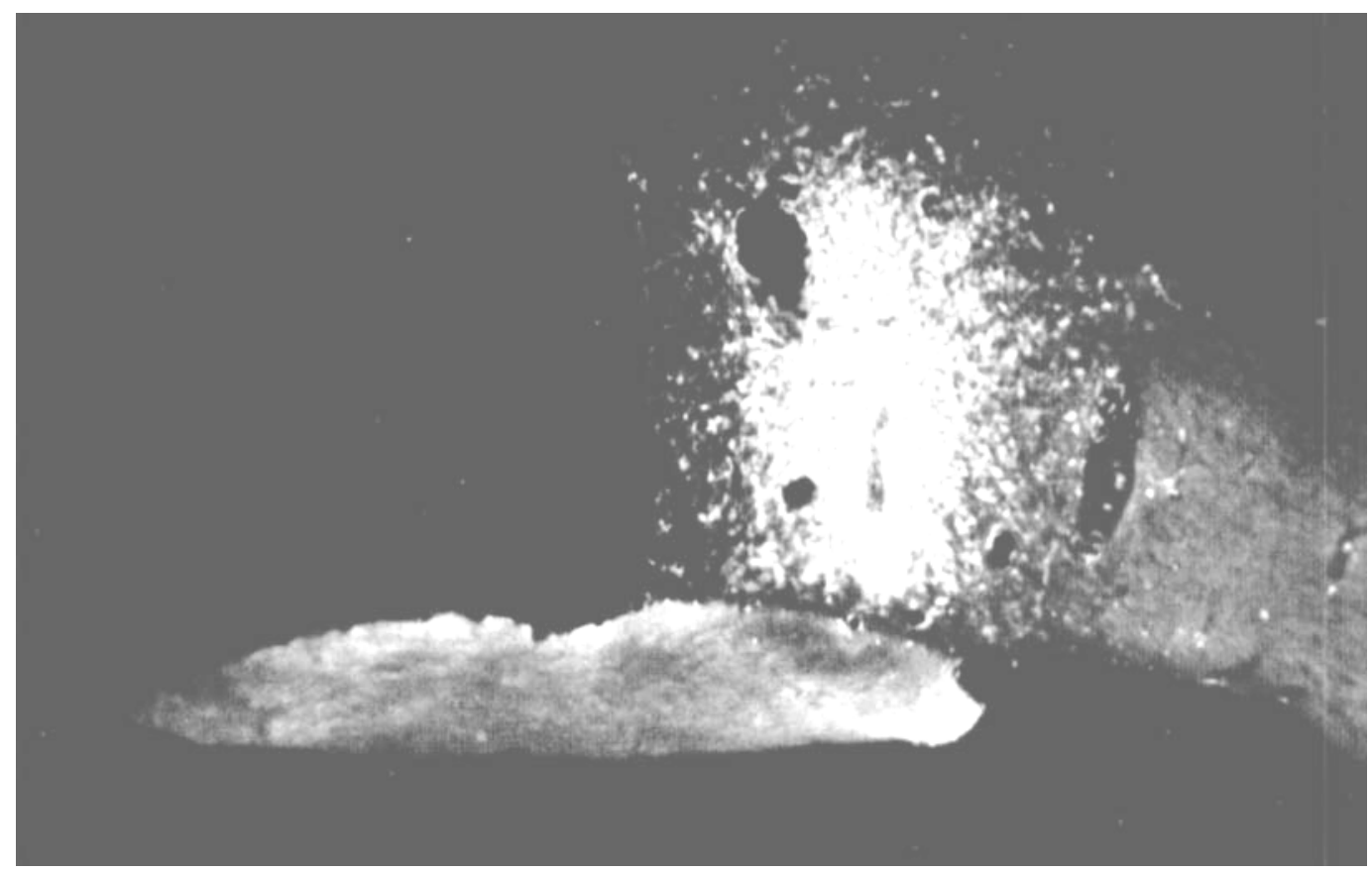

Fig. 6. HRP iontophoresis site in the medial preoptic area in male hamster brain M-7, $\times 40$ (See also Fig. 1C.)

stria terminalis. Moreover, analysis of tissue from animals that received HRP injections after the stria terminalis had been destroyed revealed no cell labeling in either the medial amygdaloid nucleus or the amygdalohippocampal area. This suggests that amygdaloid efferents to the medial preoptic area travel solely via the stria terminalis and argues against the existence of a ventral amygdalofugal pathway to the medial preoptic area, as has been demonstrated for amygdaloid efferents to the bed nucleus of the stria terminalis in the hamster (Lehman and Winans, '83).

The results of this study of pathways from the amygdala to the medial preoptic area in the hamster are similar to those for the rat. In their autoradiographic study of amygdala efferents, Krettek and Price ('78a) injected [3-H]amino acids into the medial amygdaloid nucleus and the amygdalohippocampal area and observed a terminal field in the preoptic portion of the BNST. According to the boundaries of the medial preoptic area, as defined above, what Krettek and Price describe as the preoptic bed nucleus of the stria terminalis corresponds to the dorsolateral portion of the medial preoptic area proper as we have described it in the hamster. We believe that this apparent anatomical disparity is simply a difference in terminology. In a study by Berk and Finkelstein ('81), HRP was injected into the medial preoptic area of rats. A few labeled cells were observed in the posterodorsal region of the medial amygdaloid nucleus and a greater number of cells were distributed evenly throughout the amygdalohippocampal nucleus, in agreement with our findings. A recent report by Simerly and Swanson ('86) identifying afferents to the medial preoptic nucleus by using retrograde and anterograde techniques in the rat also supports the existence of cells in the medial amygdaloid nucleus and the amygdalohippocampal area terminating in this nucleus.

The HRP tract-tracing technique has been criticized on the grounds that fibers en passant damaged by the pipette during iontophoresis are able to take up HRP and label cells, thus giving false-positive results (Herkenham and Nauta, '77). In the rat and the hamster, fibers from the medial amygdaloid nucleus and the amygdalohippocampal area travel via the stria terminalis, where they terminate in the bed nucleus of the stria terminalis, the medial preoptic area, and further caudally in the ventromedial hypothalamus and the premammillary nucleus (Krettek and Price, '78a; Kevetter and Winans, '81a; Berk and Finkelstein, '81). Degeneration studies in the rat indicate that fibers that continue caudally beyond the medial preoptic area pass through the dorsolateral aspect of the medial preoptic area beneath the fornix (deOlmos, '72). Thus to rule out the possibility that the labeling of cells in the medial amygdaloid nucleus and the amygdalohippocampal area in our material resulted from uptake of HRP by fibers en passant, we iontophoretically applied HRP at the level of the suprachiasmatic nucleus in the anterior hypothalamus and included the area surrounding the column of the fornix in our application site (Fig. 1H). In animals in which this was done, only one or two labeled cells were observed in the medial amygdaloid nucleus, and these were restricted to the ventral portion of the rostral one-third of this nucleus, an area in which we saw no labeling following HRP applications to the medial preoptic area. Most likely, these cells were filled with HRP that had been taken up by fibers en passant that travel caudally to the ventromedial hypothalamus and premammillary nucleus. In fact, studies in the rat (Krettek and Price, '78a), the cat (McBride and Sutin, '77), and the hamster (unpublished observations) indicate that the core of the ventromedial hypothalamus receives fibers that originate in the rostral region of the medial amygdaloid nucleus. Thus it seems likely that while some cells were labeled by the uptake of HRP by fibers en passant, this uptake did not contribute to cell labeling in the dorsocaudal medial amygdaloid nucleus that was ob- 


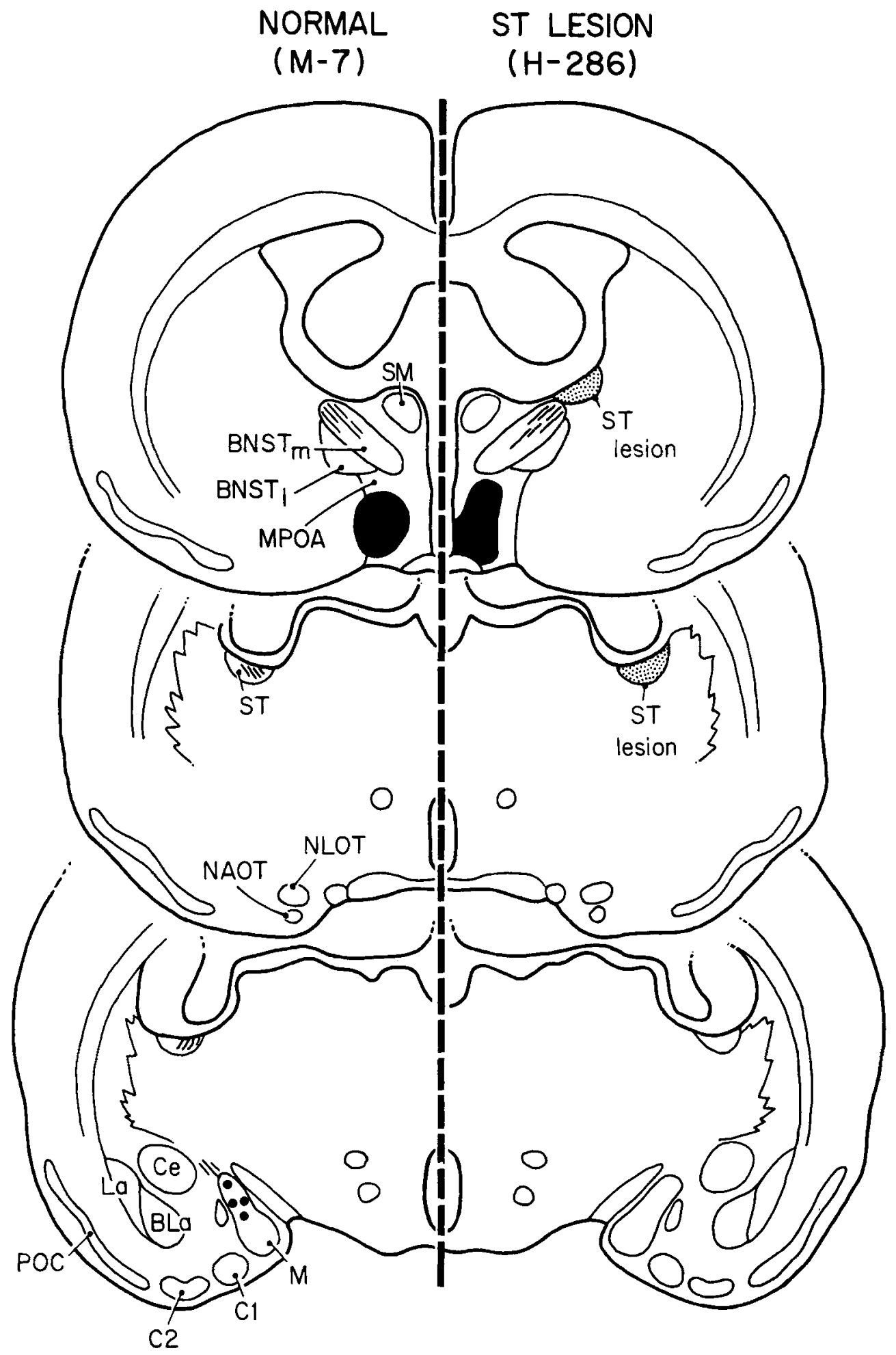

Fig. 7. Comparison of retrograde labeling in the medial amygdaloid nucleus in a normal animal (M-7; left) after iontophoresis of HRP into the medial preoptic area compared to absence of labeling in an animal in which

the stria terminalis had been destroyed (H-286; right) prior to the iontophoresis. 
served after injections into the medial preoptic area. Fur. thermore, since the anterior hypothalamus at the level of the suprachiasmatic nucleus does not receive input from the amygdala, we believe that the caudal boundary of the medial preoptic area in the hamster should be defined as the level of rostral suprachiasmatic nucleus.

Within the part of the medial preoptic area in which amygdaloid efferents terminate is a restricted region in which lesions have been shown to abolish male copulatory behavior in the hamster (Powers et al., ' 87 ). This behaviorally critical region includes the medial preoptic nucleus, the magnocellular medial preoptic nucleus, and the medial preoptic area at levels D-F in Figure 1. This suggests that the chemosensory information processed in the corticomedial amygdala (Broadwell, '75; Scalia and Winans, '75; Meredith, '80), which projects to the medial preoptic area by way of the stria terminalis, is involved in the expression of mating behavior. Two lines of evidence, however, indicate that the information traveling this route, while important, is not necessary for normal sexual behavior to occur. First, bilateral destruction of the stria terminalis does not abolish mating behavior, although this procedure does alter the temporal patterning of events during mating (Lehman et al., '83). Second, lesions to the caudal part of the medial nucleus, from which efferents to the medial preoptic area originate, do not produce severe deficits in mating behavior (Lehman et al., ' 80 ). This led us to postulate an alternate route by which that chemosensory information from the medial amygdaloid nucleus, which is critical to mating behavior, reaches the medial preoptic area. This hypothesis was supported by anatomical evidence for the existence of a ventral pathway originating in the rostral part of the medial amygdaloid nucleus and terminating in the bed nucleus of the stria terminalis (Lehman and Winans, '83) and with evidence that sectioning this ventral pathway in addition to the stria terminalis abolished all male copulatory behavior (Lehman, '82).

Taken together, these experiments focused attention on the bed nucleus of the stria terminalis as a target for the projections of the corticomedial amygdala that facilitate male sexual behavior. That the bed nucleus of the stria terminalis might provide a further projection to the medial preoptic area was suggested by data from this study, in which HRP-stained cells were observed in the bed nucleus of the stria terminalis following applications of HRP confined to the medial preoptic area (data not shown). In the rat, Simerly and Swanson ('86) have identified cells in the "encapsulated" (medial) bed nucleus of the stria terminalis after injections of fluorescent tracers into the medial preoptic area, and immunohistochemical studies have revealed a short substance-Pergic pathway from the bed nucleus of the stria terminalis to the medial preoptic area (Paxinos et al., '78). This, then, is another route by which amygdaloidprocessed chemosensory information may reach the medial preoptic area. In male hamsters, small bilateral lesions of the bed nucleus of the stria terminalis reliably produce a marked reduction in anogenital investigation of receptive female hamsters during sex behavior tests, and larger lesions of this nucleus, which include amygdalopreoptic fibers, eliminate all mating behavior (Powers et al., ' 87 ).

The amygdalopreoptic connections in the hamster demonstrated in the present HRP study arise from areas of the amygdala that actively accumulate androgens (Doherty and Sheridan, '81) and that receive both direct and indirect vomeronasal inputs (Meredith, ' 80 ; Kevetter and Winans, '81a) and indirect olfactory inputs (Kevetter and Winans,
' $81 \mathrm{~b}$ ). Lying within the territory of the medial preoptic area reached by these connections is a region critical for male hamster copulatory behavior (Powers et al., '87). Although severing the stria terminalis fibers that make these connections does not eliminate the behavior, it alters the temporal pattern of copulation (Lehman et al., '83), and combined lesions of both the ventral amygdaloid pathway to the bed nucleus of the stria terminalis and the stria terminalis do completely abolish mating. Thus, we conclude that the caudal medial amygdaloid nucleus and the amygdalohippocampal area may act as an androgen-dependent processing center for sexually relevant chemosensory information and that this information guides the temporal patterning of male reproductive behavior in the Syrian hamster.

\section{ACKNOWLEDGMENTS}

This work was supported by NIH grants NS-10471 and NS-20629 to S.W. Newman. We are indebted to William L. Brudon for the illustrations and to Sharon Moskwiak for secretarial support.

\section{LITERATURE CITED}

Berk M.L., and J.A. Finkelstein (1981) Afferent projections to the preoptic area and hypothalamic regions in the rat brain. Neuroscience 6:16011624 .

Bleier R., W. Byne, and L. Siggelkow (1982) Cytoarchitectonic sexual di morphisms of the medial preoptic and anterior hypothalamic areas in guinea pig, rat, hamster, and mouse. J. Comp. Neurol. 212:118-130.

Broadwell, R. (1975) Olfactory relationships of the telencephalon and diencephalon in the rabbit. I. An autoradiographic study of the efferent connections of the main and accessory olfactory bulbs. J. Comp. Neurol. $163: 329-345$

Brodal, A. (1947) The amygdaloid nucleus in the rat. J. Comp. Neurol. 87:116.

Caggiula, A.R., S.M. Antelman, and M.J. Zigmond (1973) Disruption of copulation in male rats after hypothalamic lesions: $A$ behavioral, anatomical and neurochemical analysis. Brain Res. 59:273-287.

Christensen, L.W., and L.G. Clemens (1974) Intrahypothalamic implants of testosterone or estradiol and the resumption of masculine sexual behavior in long-term castrated male rats. Endocrinology 95:984-990.

Christensen, L.W., D.W. Nance, and R.A. Gorski (1977) Effects of hypothalamic and preoptic lesions on reproductive behavior in male rats. Brain Res. Bull. 2:137-141.

Conrad, L.C.A., and D.W. Pfaff (1976) Efferents from medial basal forebrain and hypothalamus in the rat I. An autoradiographic study of the medial preoptic area. J. Comp. Neurol. 169:185-220.

Davidson, J.M. (1966) Activation of the male rat's sexual behavior by intracerebral implantation of androgen. Endocrinology 79:783-794.

deOlmos, J.S. (1972) The amygdaloid projection field in the rat as studied with the cupric-silver method. In. B. Eleftheriou (ed): The Neurobiology of the Amygdala. New York: Plenum Press, pp. 145-204.

deOlmos, J.S., H. Hardy, and L. Heimer (1978) The afferent connections of the accessory olfactory bulb formation in the rat: An experimental HRPstudy. J. Comp. Neurol. 181:213-243.

Doherty, P.C., and P.J. Sheridan (1981) Uptake and retention of androgen in neurons of the brain in the golden hamster. Brain Res. 219:327-334.

Eskes G.A. (1984) Neural control of the daily rhythm of sexual behavior in the male golden hamster. Brain Res. 293:127-141.

Giantonio, G.W., N.L. Lund, and A.A. Gerall (1970) Effect of diencephalic and rhinencephalic lesions on the male rat's sexual behavior. J. Comp. Physiol. Psychol. 73:38-46.

Gorski, R.A, J.H. Gordon, J.E. Shryne, and A.M. Southam (1978) Evidence for a morphological sex difference within the preoptic area of the rat brain. Brain Res.148:333-346.

Gurdjian, E.S. (1927) The diencephalon of the albino rat. Studies on the brain of the rat. No. 2. J. Comp. Neurol. 43:1-114.

Hansen, S., C. Kohler, M. Goldstein, and H.V.M. Steinbush (1982) Effects of ibotenic acid-induced neuronal degeneration in the medial preoptic area and the lateral hypothalamic area on sexual behavior in the male rat. Brain Res. 239:213-232.

Heimer L. and K. Larsson (1966) Impairment of mating behavior in male rats following lesions in the preoptic-anterior hypothalamic continuum. 
Brain Res. 3:248-263.

Herkenham, M., and W.J.H. Nauta (1977) Afferent connections of the habenular nuclei in the rat. A horseradish peroxidase study, with a note on the fiber-of-passage problem. J. Comp. Neurol. 173:123-146.

Kendrick, K.M. (1982a) The effect of castration on stria terminalis neurone absolute refractory period using antidromic stimulation loci. Brain Res. 248:174-176.

Kendrick, K.M. (1982b) Effect of castration on medial preoptic/anterior hypothalamic neurone responses to stimulation of the fimbria in the rat. J. Physiol. 323:449-461.

Kendrick, K.M., and R.F Drewett (1979) Testosterone reduces refractory period of stria terminalis neurons in the rat brain. Science 204:877-879.

Kevetter, G.A., and S.S. Winans (1981a) Connections of the corticomedial amygdala in the golden hamster. I. Efferents of the "vomeronasal amygdala." J. Comp. Neurol. 197:81-98.

Kevetter, G.A., and S.S. Winans (1981b) Connections of the corticomedial amygdala in the golden hamster. II. Efferents of the "olfactory amygdala.” J. Comp. Neurol. 197:99-111.

Krettek J.E., and J.L. Price (1978a) Amygdaloid projections to subcortical structures within the basal forebrain and brainstem in the rat and cat. J. Comp. Neurol. 178:225-254.

Krettek, J.E., and J.L. Price (1978b) A description of the amygdaloid complex in the rat and cat with observations on intra-amygdaloid axonal connections. J. Comp. Neurol. 178:255-280.

Larsson, K. (1979) Features of the neuroendocrine regulation of masculine sexual behavior. In C. Beyer (ed): Endocrine Control of Sexual Behavior. New York: Raven Press, pp. 77-163.

Lehman, M.N. (1982) Neural Pathways of the Vomeronasal and Olfactory Systems Controlling Sexual Behavior in the Male Golden Hamster. Dissertation, University of Michigan.

Lehman M.N., S.S. Winans and J.B. Powers (1980) Medial nucleus of the amygdala mediates chemosensory control of male hamster sexual behavior. Science 210:557-560.

Lehman, M.N., and S.S. Winans (1982) Vomeronasal and olfactory pathways to the amygdala controlling male hamster sexual behavior: Autoradiographic and behavioral analysis. Brain Res. 240:27-41.

Lehman, M.N., and S.S. Winans (1983) Evidence for a ventral non-strial pathway from the amygdala to the bed nucleus of the stria terminalis in the male golden hamster. Brain Res. 268:139-146.

Lehman, M.N., J.B. Powers, and S.S. Winans (1983) Stria terminalis lesions alter the temporal pattern of copulatory behavior in the male golden hamster. Behav. Brain Res. 8:109-128.

Leonard, C.M., and J.W. Scott (1971) Origin and distribution of the amygdalofugal pathways in the rat: An experimental neuroanatomical study. J. Comp. Neurol. 141:313-330.

Lisk R.D. (1967) Neural localization for androgen activation of copulatory behavior in the male rat. Endocrinology 80:754-761.

Lisk, R.D. (1968) Copulatory activity of the male rat following placement of preoptic-anterior hypothalamic lesions. Exp. Brain Res. 5:306-313.

Lisk, R.D., and J.L. Bezier (1980) Intrahypothalamic hormone implantation and activation of sexual behavior in the male hamster. Neuroendocrinology 30:220-227.

Malsbury, C.W. (1971) Facilitation of male rat copulatory behavior by electrical stimulation of the medial preoptic area. Physiol. Behav. 7:797805.

Malsbury, C.W., and D.W. Pfaff (1975) Neural and hormonal determinants of mating behavior in adult male rats. A review. In L.D. DiCara (ed): Limbic and Autonomic Nervous Systems Research. New York: Plenum Press, pp. 85-136.
McBride, R.L., and J. Sutin (1977) Amygdaloid and pontine projections to the ventromedial nucleus of the hypothalamus. J. Comp. Neurol. 174:377-396.

Merari A. and A. Ginton (1975) Characteristics of exaggerated sexual be havior induced by electrical stimulation of the medial preoptic area in male rats. Brain Res. 86:97-108.

Meredith, M. (1980) The vomeronasal organ and accessory olfactory system in the hamster. In D. Muller-Schwarze and R.M. Silverstein (eds): Chemical Signals in Vertebrates and Aquatic Invertebrates. New York: Plenum Press, pp. 303-326.

Murphy, M.R., and G.E. Schneider (1970) Olfactory bulb removal eliminates mating behavior in the male golden hamster. Science 167:302-304.

Newman, R., and S.S. Winans (1980) An experimental study of the ventral striatum of the golden hamster. I. Neuronal connections of the nucleus accumbens. J. Comp. Neurol. 191:167-192.

Nishizuka, M., and Y. Arai (1981a) Sexual dimorphism in synaptic organization in the amygdala and its dependence on neonatal hormone environment. Brain Res. 212:31-38.

Nishizuka, M., and Y. Arai (1981b) Organizational action of estrogen on synaptic pattern in the amygdala: Implications for sexual differentia tion of the brain. Brain Res. 213:422-426.

Ottersen O.P. (1980) Afferent connections to the amygdaloid complex of the rat and cat: II. Afferents from the hypothalamus and the basal telen cephalon. J. Comp. Neurol. 194:267-289.

Ottersen, O.P. (1982) Connections of the amygdala of the rat. IV. Corticoamygdaloid and intra-amygdaloid connections as studied with axonal transport of horseradish peroxidase. J. Comp. Neurol, 205:30-48.

Paxinos, G., P.C. Emson, and A.C. Cuello (1978) Substance-P projections to the entopeduncular nucleus, the medial preoptic area and the lateral septum. Neurosci. Lett. 7:133-136.

Powers, J.B., S.W. Newman, and M.L. Bergondy (1987) MPOA and BNST lesions in male Syrian hamsters: Differential effects on copulatory and chemoinvestigatory behaviors. Behav. Brain Res. 23:181-195.

Saper, C.B., L.W. Swanson, and W.M. Cowan (1978) The afferent connections of the anterior hypothalamic area of the rat, cat and monkey. J. Comp. Neurol. 182:575-599.

Sar M. and W.E. Stumpf (1975) Distribution ot androgen-concentrating neurons in rat brain. In W.E. Stumpf and L.D. Grant (eds): Anatomical Neuroendocrinology. Basel: Karger, pp. 120-133.

Sar, M., and W.E. Stumpf (1977) Distribution of androgen target cells in rat forebrain and pituitary after ${ }^{3} \mathrm{H}-\mathrm{DHT}$ administration. J. Steroid Biochem. 8:1131-1135.

Scalia, F., and S.S. Winans (1975) The differential projections of the olfac tory bulb and accessory olfactory bulb in mammals. J. Comp. Neurol. 161:31-56.

Simerly, R.B., and L.W. Swanson (1986) The organization of neural inputs to the medial preoptic nucleus of the rat. J. Comp. Neurol. 246:312-342

Simerly, R.B., L.W. Swanson, and R.A. Gorski (1984) Demonstration of a sexual dimorphism in the distribution of serotonin-immunoreactive fibers in the medial preoptic nucleus of the rat. J. Comp. Neurol. 225:151166.

Swanson, L.W. (1976) An autoradiographic study of the efferent connections of the preoptic region in the rat. J. Comp. Neurol. 167:227-256.

Szechtman, H., A.R. Caggiula, and D. Wulkan (1978) Preoptic knife cuts and sexual behavior in male rats. Brain Res. 150:569-591.

Winans S.S. and J.B. Powers (1977) Olfactory and vomeronasal deafferen tation of male hamsters: Histological and behavioral analyses. Brain Res. 126:325-344. 